\title{
Assessing Knowledge, Attitudes and Practices Towards COVID-19 Public Health Preventive Measures Among Patients at Mulago National Referral Hospital
}

This article was published in the following Dove Press journal:

Risk Management and Healthcare Policy

\section{Nelson Twinamasiko $\mathbb{D}$ \\ Ronald Olum (D) \\ Anna Maria Gwokyalya \\ Innocent Nakityo \\ Enock Wasswa \\ Emmanuel Sserunjogi}

School of Medicine, College of Health Sciences, Makerere University, Kampala, Uganda
Correspondence: Nelson Twinamasiko School of Medicine, College of Health Sciences, Makerere University, P.O. Box 7062, Kampala, Uganda

Tel +256755260763

Email drtwinamasikonelson@gmail.com
Background: COVID-19 has become a major global health challenge, with Uganda reporting over 20,000 cases. There is, however, a scarcity of data on the perception of patients in Uganda towards the highly infectious disease. We aimed to assess the awareness, knowledge, attitudes, and practices towards COVID-19 preventive measures among patients at Mulago National Referral Hospital (MNRH), Uganda.

Methods: A cross-sectional quantitative survey was conducted in August, 2020, among patients in surgical and medical wards at MNRH. An interviewer-administered, pre-validated questionnaire was used to collect data that was entered into Google Forms and analyzed using Microsoft Excel and STATA 16. Descriptive statistics was used to present data from univariate analysis. Patients whose knowledge and practice scores were greater or equal to the average score were regarded to have good knowledge and practices respectively. Chisquare, Fisher's Exact tests and binary logistic regression were used to assess factors associated with COVID-19 knowledge and practices. A $\mathrm{P}<0.05$ was statistically significant. Results: Overall, 114 patients were approached and 102 consented to participate. Most were females $(53.8 \%)$, aged above 45 years $(31.4 \%)$ with $40.2 \%$ reporting primary level as the highest level of education. About 55.9\% $(n=57)$ had adequate knowledge for COVID-19 and its related practices, and 52\% $(n=53)$ had good COVID-19 related practices. Knowledge significantly differed by marital status at bivariate analysis $(\mathrm{P}=0.020)$, however this lost significance at logistic regression. Female patients were thrice more likely to have good COVID-19 prevention practices compared to males (COR: 2.59, 95\% CI: 1.2 to 5.8, $\mathrm{P}=0.020)$. Some $47(46.1 \%)$ participants perceived that COVID-19 preventive measures were not difficult at all to observe.

Conclusion: About half of the patients at Mulago National Referral Hospital lack adequate knowledge and practice on COVID-19 prevention. Continued patient education is required to increase knowledge which will in turn improve adherence to COVID-19 preventive practices.

Keywords: COVID-19, knowledge, attitudes, practices, patients, Uganda

\section{Introduction}

Coronavirus disease 2019 (COVID-19) is an illness caused by a coronavirus, currently known as Severe Acute Respiratory Syndrome Coronavirus 2 (SARSCoV-2). COVID-19 was first identified in Wuhan city, China in late December, 2019 and has since become a global pandemic, with cases in over 200 countries. $^{1,2}$ 
As of November 24, 2020, it had infected over 57 million people and had caused over 1 million deaths globally. ${ }^{3}$ The most common manifestations of COVID-19 are difficulty in breathing, fever, tiredness, muscle aches and pain, and dry cough. ${ }^{4}$ People with co-morbidities like diabetes, hypertension and those who are of advanced age have been pointed out as being likely risk factors for dreadful illness and mortality. ${ }^{5}$

Currently, there is no approved vaccination or curative treatment for COVID-19, ${ }^{6}$ however, as per November 20 , 2020, several vaccines are under advanced testing for possible use and the current treatment is only supportive. Several measures have been set up to control the transmission of COVID-19 and its disastrous consequences on the public and health systems. Some of the measures have included: limitation of movements with lock down measures, self-isolation in addition to quarantine of the suspected cases, hand washing with soap and use of facemasks. The triumph of those preventive actions is, however, determined by the populations' compliance to the guidelines which is in turn determined by their knowledge and attitude. ${ }^{7}$

Uganda registered her first case of COVID-19 on March 21, 2020. ${ }^{8}$ Between March 18 and June 1, 2020, Uganda's government declared several measures in order to prevent virus transmission and manage the few cases that the country had at that time. ${ }^{8}$ These included strict measures like shutdown of all border movements and educational institutions, restriction on all public gatherings, and a nation-wide lockdown restricting any movements of people except those who were providing essential services. However, upon relaxation of the measures, the Ministry of Health (MOH) documented a surge in the new positive cases from within the population whose origin of infection could not be tracked down easily. $\mathrm{MOH}$ Uganda has since reported over 17,000 cases and over 158 deaths as of November 20, 2020. ${ }^{3}$ Although the government has directed implementation of social distancing in all public places and wearing of face masks, adherence by the public has been questionable. ${ }^{8,9}$ Despite this, the increase of the number of confirmed cases with COVID-19 has been of less worry to people. ${ }^{10}$

Uganda, just like other developing countries is faced with challenges like inadequate resources in order to take care of the huge number of COVID-19 infected patients in contrast to developed countries. Therefore, compliance to preventive measures would reduce the burden to the healthcare systems in low-resourced countries,
Uganda included. A study by Zhang and colleagues showed that patients with comorbidities (especially chronic diseases like diabetes) are more vulnerable to a dreadful form of COVID-19, hence considering them as the high risk group. ${ }^{11}$ Inadequate knowledge of the disease in high risk groups has been implicated in the increase of the death toll due to the disease, therefore, successful containment and lessening of mortality due to COVID-19 necessitates behavioral change, which is directly determined by perception and knowledge of the people. $^{12}$

Patients in hospitals are also at high risk of contracting COVID-19 from other patients or the healthcare workers, especially in national referral hospitals who admit patients from diverse sociodemographic backgrounds. There are however limited studies in sub-Saharan Africa and globally, reporting knowledge, attitudes, and practices (KAPs) of patients towards COVID-19. Among patients with chronic diseases in Ethiopia, poor knowledge and practices towards COVID-19 were significantly high. ${ }^{13}$ In Uganda, studies on COVID-19 related KAPs have been limited to healthcare workers, university students and market vendors. ${ }^{14-16}$ In this study, we aimed to assess the level of KAPs towards COVID-19 preventive measures among patients admitted in the medical and surgical wards of Mulago National Referral Hospital (MNRH), Uganda's largest public hospital.

\section{Methodology Study Design}

A descriptive cross-sectional survey using quantitative techniques was conducted in August, 2020 over two weeks from August 11, 2020 to August 25, 2020.

\section{Study Site and Population}

The study was carried out in Mulago Hospital which is the largest national referral and doubles as the teaching hospital for Makerere University. The hospital is located on Mulago Hill, 5 kilometers by road north of Kampala city. MNRH has both outpatient and inpatient departments offering services in most surgical and medical subspecialties, in addition to dentistry, emergency medicine, pediatrics, and intensive care. The study was done in three wards which were selected randomly: gastrointestinal surgical, neurosurgery and medical wards. Each ward contained a minimum of 45 patients at the time of the study. 


\section{Selection Criteria}

Patients who were 18 years and above, admitted in the gastrointestinal surgical, neurosurgery and medical wards at MNRH who had consented to take part in the study were eligible. Patients who were severely ill subjectively and were mentally incapacitated to respond to the survey were excluded.

\section{Data Collection}

An interviewer-administered questionnaire was used to collect data from the eligible participants. A translator was as well provided to those who could not understand English because the questionnaire was in English language only. Appendix II is the questionnaire which was used in collecting the data. Patients were conveniently selected based on their physical and mental health condition. The three wards had a total 143 patients, of which 114 were considered eligible to participate in the study. Forty-one patients were from the gastrointestinal surgery ward, 25 from neurosurgery ward and 36 from the medical ward. Data was collected over two weeks.

The questionnaire was developed according to the guidelines for community of COVID-19, by the Centers for Disease Control and Prevention (CDC) and World Health Organization. The questionnaire consisted of four sections:

(i) six questions on socio-demographic characteristics;

(ii) ten questions for knowledge and awareness about COVID-19;

(iii) five questions on attitudes towards the measures put in place to prevent the spread of COVID-19; and

(iv) eight questions on practices towards the preventive measures put in place.

\section{Data Processing and Analysis}

Fully completed questionnaires were entered into Microsoft Excel 2016 for coding and cleaning. The coded and cleaned data was thereafter exported to STATA 16 (StataCorp LLC, College Station, TX, USA) for analysis. Independent variables were summarized as frequencies and percentages. Questions on knowledge and practices were categorized into correct and incorrect answers. Each correct answer obtained 1 point and incorrect ones were awarded 0 points, with a maximum total score of 27. The total scores for questions on knowledge were converted to percentage and knowledge was thereafter categorized. Participants who scored above the mean score $(\geq 50.6 \%$ ) were considered to have adequate knowledge and below $50.6 \%$ was considered poor/inadequate knowledge. For practice, the practice scores were not normally distributed and a median score of $75 \%$ was taken as the cutoff. Those who scored $\geq 75 \%$ were considered to have good COVID-19 related practices whereas below 75\% had poor practices. Responses for attitudes were presented as frequencies and percentages. Chisquare test or Fisher's Exact tests were applied to assess the factors associated with good knowledge on COVID-19 at bivariate analysis. A binary logistic regression was used to assess the strength of the association of risk factors which were significant at bivariate analysis with knowledge and practice and presented as crude odds ratio (COR) with a 95\% confidence interval (CI) and p-values. A $\mathrm{P}<0.05$ was considered statistically significant.

\section{Safety Precautions}

Face masks were worn by the research assistants who were distributing the questionnaire as per the guidelines for prevention of COVID-19. In order to minimize further risks of COVID-19 transmission, participants' hands were sanitized before and after giving them the paper questionnaire. Face masks were also provided to patients who were not wearing them and the recommended social distance was observed between the study staff and participants.

\section{Ethical Considerations}

The study was approved by Mulago Hospital Institutional Review Board (Protocol Number: MHREC 1900). Additional permissions were sought from the hospital administration and the ward in-charges. The study was conducted according to the Declaration of Helsinki. All participants provided a written informed consent prior to participating in the study. Appendix I is the informed consent form used in collecting consent from the study participants.

\section{Supplementary Material}

The Supplementary Material for this article contains Appendix I and Appendix II. Appendix I shows the informed consent form used in collecting consent from the study participants. Appendix II shows the questionnaire used in collecting data. 


\section{Results}

\section{Demographics}

A total of 102 participants were involved in this study. Of these, the majority were females (53.9\%) and the majority age range was above 45 years. Regarding the educational status, most of the respondents $(40.25 \%, \mathrm{n}=41)$ ended their education at primary level. $75.4 \%$ resided in the central region of Uganda, $52.9 \%$ were self-employed and $54.9 \%$ were married. Table 1 presents the socio-demographics of the participants. Of the 102 participants, a majority $(94.12 \%)$ responded that they were aware that COVID-19 exists as presented.

Table I Socio-Demographic Characteristics of Study Participants

\begin{tabular}{|c|c|c|}
\hline Demographics $(\mathrm{N}=\mid 02)$ & Frequency & $\%$ \\
\hline \multicolumn{3}{|l|}{ Age in years } \\
\hline $18-24$ & 25 & 24.5 \\
\hline $25-34$ & 16 & 15.7 \\
\hline $35-44$ & 29 & 28.4 \\
\hline$\geq 45$ & 32 & 31.4 \\
\hline \multicolumn{3}{|l|}{ Sex } \\
\hline Female & 55 & 53.9 \\
\hline Male & 47 & 46.1 \\
\hline \multicolumn{3}{|l|}{ Marital status } \\
\hline Married & 56 & 54.9 \\
\hline Single & 36 & 35.3 \\
\hline Divorced & 7 & 6.9 \\
\hline Widowed & 3 & 2.9 \\
\hline \multicolumn{3}{|l|}{ Occupation } \\
\hline Self-employed & 54 & 52.9 \\
\hline Not employed & 20 & 19.6 \\
\hline Employed & 19 & 18.6 \\
\hline Student & 9 & 8.8 \\
\hline \multicolumn{3}{|l|}{ Level of education } \\
\hline Primary & 41 & 40.2 \\
\hline Secondary (O-level) & 32 & 31.4 \\
\hline Secondary (A-level) & 7 & 6.9 \\
\hline Diploma & 10 & 9.8 \\
\hline Bachelor's Degree & 12 & 11.8 \\
\hline \multicolumn{3}{|l|}{ Region of origin } \\
\hline Central & 76 & 74.5 \\
\hline Western & 12 & 11.8 \\
\hline Eastern & 9 & 8.8 \\
\hline Northern & 5 & 4.9 \\
\hline \multicolumn{3}{|l|}{ Are you aware that COVID- 19 exists? } \\
\hline Yes & 96 & 94.1 \\
\hline No & 3 & 2.9 \\
\hline Maybe & 3 & 2.9 \\
\hline
\end{tabular}

\section{Knowledge}

About $81 \%$ of the participants reported cough as being the most common symptom as summarized in Figure 1.

Table 2 shows responses of the participants to questions about knowledge on COVID-19. The majority (83.3\%, $\mathrm{n}=85$ ) of the participants reported that everyone was at risk of getting COVID-19 and one-third $(66.7 \%, \mathrm{n}=68)$ reported that people of age $\geq 45$ years and those with other diseases were at the highest risk of severe illness of COVID-19. Only $61.8 \%$ and $45.1 \%$ knew that COVID-19 did not currently have a vaccine nor a cure, respectively. Overall, 55.9\% $(n=57)$ of the participants scored $50 \%$ or more and were regarded as having adequate knowledge (Table 3).

At Fisher's Exact test analysis, marital status was significantly associated with knowledge $(\mathrm{P}=0.020)$ but this lost significance at logistic regression [married (COR: 1.2, 95\% CI: 0.5 to $2.8, \mathrm{P}=0.695$ ); and divorced (COR: 0.11, 95\% CI: 0.01 to $1.1, \mathrm{P}=0.06)$ ]; with patients who have never married as the reference.

\section{Practices}

Whereas $64.7 \%(n=66)$ of the respondents reported that they always wore a mask when in public, only $22.6 \%$ could maintain the 2 meters of social distance. Some $59.8 \%$ always often wash their hands with soap and $78.4 \%$ always cover their nose and mouth with either a handkerchief or crease of elbow (Table 4).

Overall, about half $(52 \%, \mathrm{n}=53)$ of the participants were regarded to have good COVID-19 related practices (Table 3).

At bivariate analysis (chi-square or Fisher's Exact test), sex $(\mathrm{P}=0.031)$ and awareness about COVID-19 existence $(\mathrm{P}=0.010)$ were significantly associated with good COVID-19 related practices (Table 3). Age, marital status, occupation and level of education were not statistically significant.

At binary logistic regression, female patients were thrice more likely to have good COVID-19 prevention practices compared to their male counterparts (COR: 2.59, 95\% CI: 1.2 to $5.8, \mathrm{P}=0.020$ ). Patients with good knowledge were twice more likely to have good practices although this was not statistically significant $(\mathrm{COR}=1.72$, 95\% CI: 0.78 to $3.78, \mathrm{P}=0.178$ ).

\section{Attitudes}

The majority of the participants had a good attitude towards the authenticity of COVID-19 tests (Table 5). 


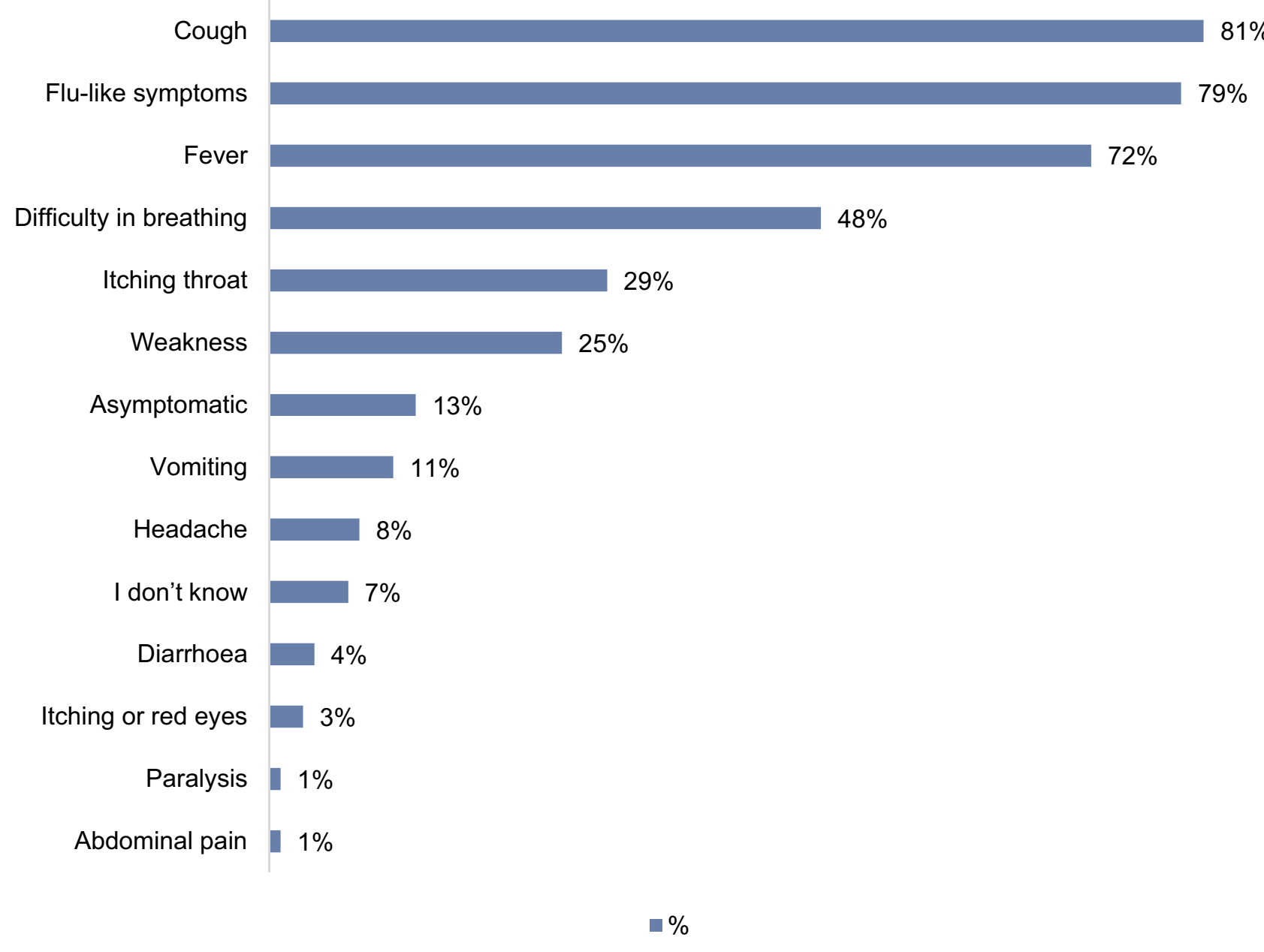

Figure I Knowledge of Participants on the symptoms of COVID-19 ( $\mathrm{N}=102)$. Data shows majority of the participants $(81 \%)$ knew cough as the most common symptom of COVID-19.

About $56.9 \%$ of the participants rated government's efforts of controlling the spread of COVID-19 as being good and $82.4 \%$ thought that nation-wide lockdown helped in controlling the spread of COVID-19 (Table 5). Less than half of the participants (46.1\%) as well thought that the COVID-19 preventive measures of staying at home, wearing face mask, hand hygiene and social distance were not difficult at all to practice (Table 5).

\section{Discussion}

The rapid transmission of COVID-19 is a major public health issue in Uganda and the world, especially after easing the extreme and strict preventive measures like lockdowns. Currently no vaccine or treatment has been officially approved for use against COVID-19, hence making prevention a better option in the fight against COVID-19. For prevention to be successful, the population should have a good understanding of the pandemic coupled with good attitudes towards the preventive measures. Therefore, this study was done to assess the level of knowledge, attitudes and practices of COVID-19 preventive measures among inpatients at Mulago hospital.

From the study, we found that more than half of the respondents had adequate knowledge of COVID-19 and its preventive measures. This finding was similar to studies done by Zhong and colleagues among Chinese residents, ${ }^{17}$ and Olum et al, among Ugandan healthcare workers. ${ }^{15}$ However, it is in contrast to the study done by Akalu and colleagues which showed a high prevalence of poor knowledge among chronic diseases patients in Addis Zemen Hospital, Northwest Ethiopia. ${ }^{13}$ This could be due to the reason that the country was from a nation-wide lockdown due to COVID-19 and the Ministry of Health educative messages on COVID-19 that were disseminated countrywide during the lockdown. In addition, a majority of the respondents were aware that COVID-19 exists. This 
Table 2 COVID-19 Related Knowledge Among Patients at Mulago Hospital

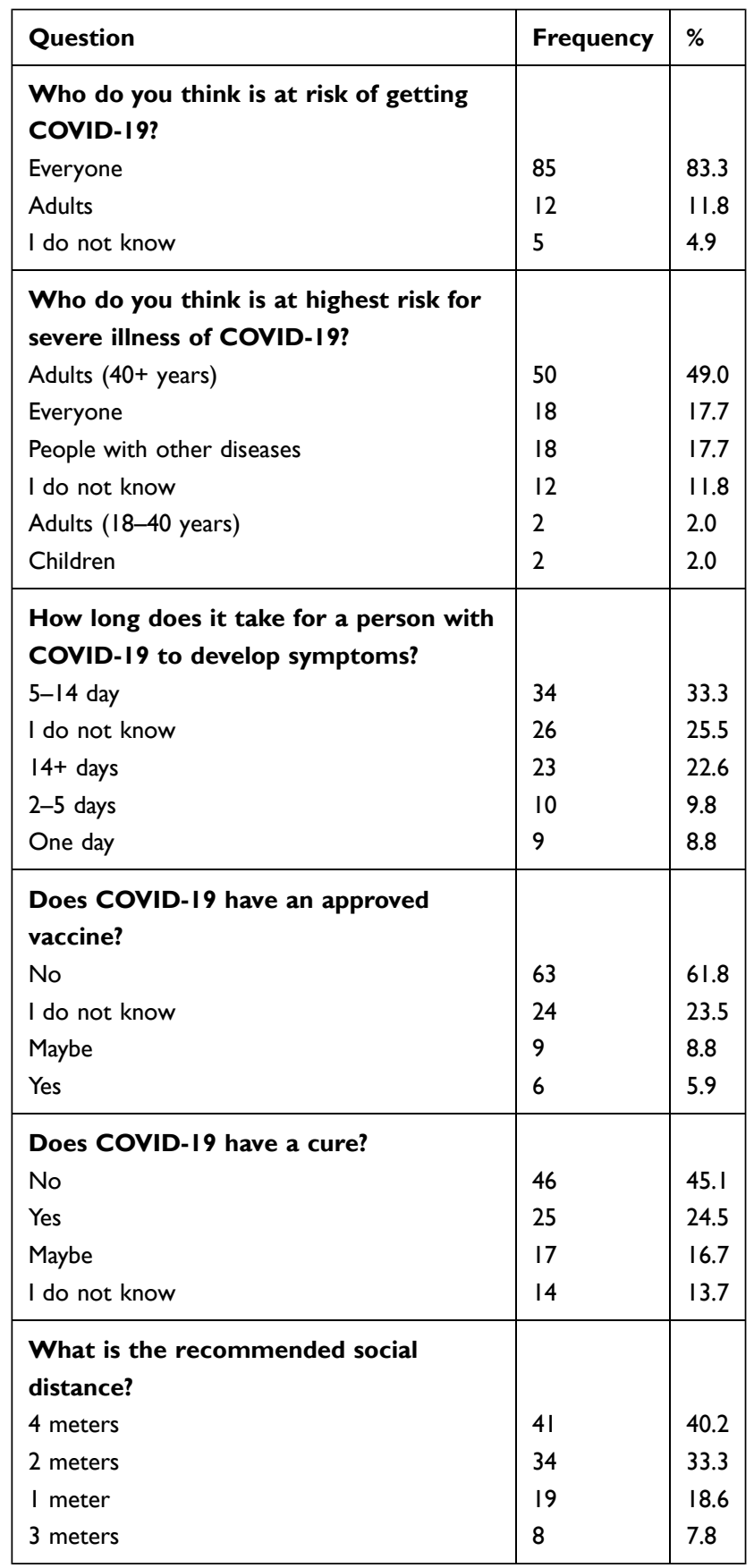

was similar to the study done in India on mental illness patients $^{18}$ and that done in China among workers. ${ }^{19}$ Cough, flu-like symptoms and fever were the most commonly known symptoms of COVID-19. This finding is in relation with studies done by Huynh et al, and Reuben et al, which indicated adequate knowledge towards COVID-19 symptoms. ${ }^{20,21}$ Though $55.9 \%$ of the respondents had adequate knowledge, the $44.1 \%$ with poor knowledge is quite significant to be ignored given the fact that the country had just relaxed the COVID-19 preventive measures. Therefore, continued education of the public on COVID-19 and its preventive measures is greatly needed. Patients with good knowledge were 9 times more likely to have good practices as evidenced in Table 5. This association can be elucidated by the reasoned action theory. ${ }^{22}$

From our study, some $7.8 \%$ of the participants said that they would not believe they are COVID-19 positive once their results come positive. This is indicative of the negative attitudes held by these respondents. However, the majority responded that they would believe, hence having good attitudes. This finding is in line with studies done on Ugandan medical students that showed positive attitudes among $74 \%$ of the participants. ${ }^{14}$ From the study, we also found out that majority of the respondents rated the government's efforts in preventing transmission of COVID-19 as being good. This could have been due to the quick and efficient actions the government of Uganda took towards preventing COVID-19. This finding was similar to the study done in Malaysia and in China where the authors credited the positive attitudes to the rigorous measures their governments put in combating the COVID-19 transmission. ${ }^{19,23}$ From our study as well, majority of the respondents thought that the lockdown helped in controlling COVID-19 transmission. This finding is in relation with the study done by Atalan where he concluded that COVID-19 can be subdued by a lockdown. ${ }^{24}$ Furthermore, a majority of the respondents thought that the government was right to put up the measures it did to prevent COVID-19 transmission. This could be attributed to the presidential addresses before any measure was instituted in addition to the constant engagement of the public on COVID-19 prevention by the Ministry of Health.

The Ministry of Health directed people with flu-like symptoms to always stay at home, however, from this study it was found that most of the participants that had had at least flu-like symptoms prior to the study never stayed at home as directed. This could be due to the fact that most of the people survive on menial and hand-tomouth jobs hence staying at home being impossible for their survival. With this result, therefore, government should make testing facilities available to every individual for quick detection of the infected people before they transmit the virus to a bigger population.

Ministry of Health also prohibited people being in public gatherings/places unnecessarily, however from this study, most of the participants had been in public 
Table 3 Factors Associated with Knowledge and Practices Towards COVID-I9

\begin{tabular}{|c|c|c|c|c|c|c|}
\hline \multirow[t]{2}{*}{ Variables $(\mathrm{N}=102)$} & \multicolumn{3}{|c|}{ Knowledge; Frequency (\%) } & \multicolumn{3}{|c|}{ Practices; Frequency (\%) } \\
\hline & Good $(n=57)$ & Poor $(n=45)$ & $\mathbf{P}$ & Good $(n=53)$ & Poor $(n=49)$ & $\mathbf{P}$ \\
\hline Overall & $57(55.9)$ & $45(44.1)$ & & $53(52)$ & $49(48)$ & \\
\hline \multicolumn{7}{|l|}{ Age in years } \\
\hline $18-24$ & $15(26.3)$ & $10(22.2)$ & 0.365 & $15(28.3)$ & $10(20.4)$ & 0.740 \\
\hline $25-34$ & $9(15.8)$ & $7(15.6)$ & & $7(13.2)$ & $9(18.4)$ & \\
\hline $35-44$ & $19(33.3)$ & $10(22.2)$ & & $14(26.4)$ & $15(30.6)$ & \\
\hline$\geq 45$ & $14(24.6)$ & $18(40)$ & & $17(32.1)$ & $15(30.6)$ & \\
\hline \multicolumn{7}{|l|}{ Sex } \\
\hline Female & $32(56.1)$ & $23(51.1)$ & 0.613 & $34(64.2)$ & $21(42.9)$ & 0.031 \\
\hline Male & $25(43.9)$ & $22(48.9)$ & & $19(35.8)$ & $28(57.1)$ & \\
\hline \multicolumn{7}{|l|}{ Marital status } \\
\hline Married & $35(61.4)$ & $21(46.7)$ & 0.020 & $31(58.5)$ & $25(5 \mathrm{I})$ & 0.374 \\
\hline Single & $21(36.8)$ & $15(33.3)$ & & $18(34)$ & $18(36.7)$ & \\
\hline Divorced & I (I.8) & $6(13.3)$ & & $4(7.5)$ & $3(6.1)$ & \\
\hline Widowed & $0(0)$ & $3(6.7)$ & & $0(0)$ & $3(6.1)$ & \\
\hline \multicolumn{7}{|l|}{ Occupation } \\
\hline Self-employed & $32(56.1)$ & $22(48.9)$ & 0.743 & $27(50.9)$ & $27(55.1)$ & 0.939 \\
\hline Not employed & $9(15.8)$ & II (24.4) & & $10(18.9)$ & $10(20.4)$ & \\
\hline Employed & II (19.3) & $8(17.8)$ & & II (20.8) & $8(16.3)$ & \\
\hline Student & $5(8.8)$ & $4(8.9)$ & & $5(9.4)$ & $4(8.2)$ & \\
\hline \multicolumn{7}{|l|}{ Level of education } \\
\hline Primary & $20(35.1)$ & $21(46.7)$ & 0.268 & $22(4 \mid .5)$ & $19(38.8)$ & 0.252 \\
\hline Secondary (O-level) & $16(28.1)$ & $16(35.6)$ & & $18(34)$ & $14(28.6)$ & \\
\hline Secondary (A-level) & $6(10.5)$ & I (2.2) & & $5(9.4)$ & $2(4.1)$ & \\
\hline Diploma & $7(12.3)$ & $3(6.7)$ & & $2(3.8)$ & $8(16.3)$ & \\
\hline Bachelor's Degree & $8(14)$ & $4(8.9)$ & & $6(11.3)$ & $6(12.2)$ & \\
\hline \multicolumn{7}{|l|}{ Region of origin } \\
\hline Central & $43(75.4)$ & $33(73.3)$ & 0.906 & $37(69.8)$ & $39(79.6)$ & 0.342 \\
\hline Western & $7(12.3)$ & $5(11.1)$ & & $9(17)$ & $3(6.1)$ & \\
\hline Eastern & $5(8.8)$ & $4(8.9)$ & & $5(9.4)$ & $4(8.2)$ & \\
\hline Northern & $2(3.5)$ & $3(6.7)$ & & $2(3.8)$ & $3(6.1)$ & \\
\hline \multicolumn{7}{|l|}{ Are you aware that COVID-19 exists? } \\
\hline Maybe & $\mathrm{I}(1.8)$ & $2(4.4)$ & 0.098 & $0(0)$ & $3(6.1)$ & 0.010 \\
\hline No & $0(0)$ & $3(6.7)$ & & $0(0)$ & $3(6.1)$ & \\
\hline Yes & $56(98.2)$ & $40(88.9)$ & & $53(100)$ & $43(87.8)$ & \\
\hline
\end{tabular}

gatherings of more than 2 people on the day of the study. This could have been due to the fact that the wards where the study was being conducted were congested and the patients were from different areas of residence given that the hospital is a national referral. With this, therefore, there should be expansion of the treatment units of inpatients in order to reduce congestion while in the wards.

While assessing the wearing of masks whenever in public, most of the participants reported to at least wear a face mask whenever they had gone to public places. This finding is in contrast with the study done by Echoru and colleagues, that indicated reluctance of wearing facemasks among some faith groups in Uganda. ${ }^{25}$ This variation can be explained by the fact that the two studies were carried out at different times of the pandemic. The study done by Echoru and colleagues was carried out in April 2020 when the pandemic was not very widespread in Uganda and the publicity of the disease was relatively low. In addition by 
Table 4 Practices of Patients at Mulago Hospital Towards COVID-19 Preventive Measures

\begin{tabular}{|l|l|l|}
\hline Practices & Frequency & $\%$ \\
\hline I stay home when I feel flu-like symptoms & & \\
No & 72 & 70.6 \\
Yes & 30 & 29.4 \\
\hline When I cough or sneeze, I cover my mouth & & \\
and nose with the: & & \\
Tissue paper or Handkerchief. & 56 & 54.9 \\
Crease of Elbow. & 24 & 23.5 \\
Hands. & 22 & 21.6 \\
\hline How often do you wash your hands with soap? & & \\
Always & 61 & 59.8 \\
Sometimes & 4 I & 40.2 \\
Approximately how many times did you wash & 7 & 0 to \\
your hands or use a hand sanitizer yesterday & & 20 \\
(median, range)? & & \\
\hline When was the last time you were in a public & & \\
gathering/place with more than 2 people? & & \\
Today & 9 I & 89.2 \\
Last two days & 6 & 5.9 \\
More than one week ago & 3 & 2.9 \\
Last 3 to 6 days & 2 & 2.0 \\
\hline When in the public, I wore the face mask & & \\
Always & 66 & \\
Sometimes & 35 & \\
Never & 1.0 \\
\hline When in public, I maintain a distance of at least & & \\
2 meters between us & 57.6 \\
Yes, Sometimes & \\
Yes, Always & \\
No, Never & \\
\hline
\end{tabular}

the time our study was done, the government of Uganda had distributed free masks for use to the public, hence easing accessibility of these face masks. When asked how many times they washed their hands the previous day, the median time was 7 with a range of 0 to 20 times. This was because the hospital provided hand washing supplies and everyone was required to wash their hands before and after entering the wards.

Overall, from our study, it was found that about half of the respondents practiced COVID-19 preventive measures adequately. This finding is in relation with the study done by Olum and colleagues among medical students in Uganda with the prevalence of good practices at $57 \% .{ }^{14}$ The finding was as well similar to the study done in Pakistan among healthcare workers ${ }^{26}$ and in contrast to
Table 5 Attitudes of Patients at Mulago Hospital Towards COVID-19 Diagnosis and Prevention

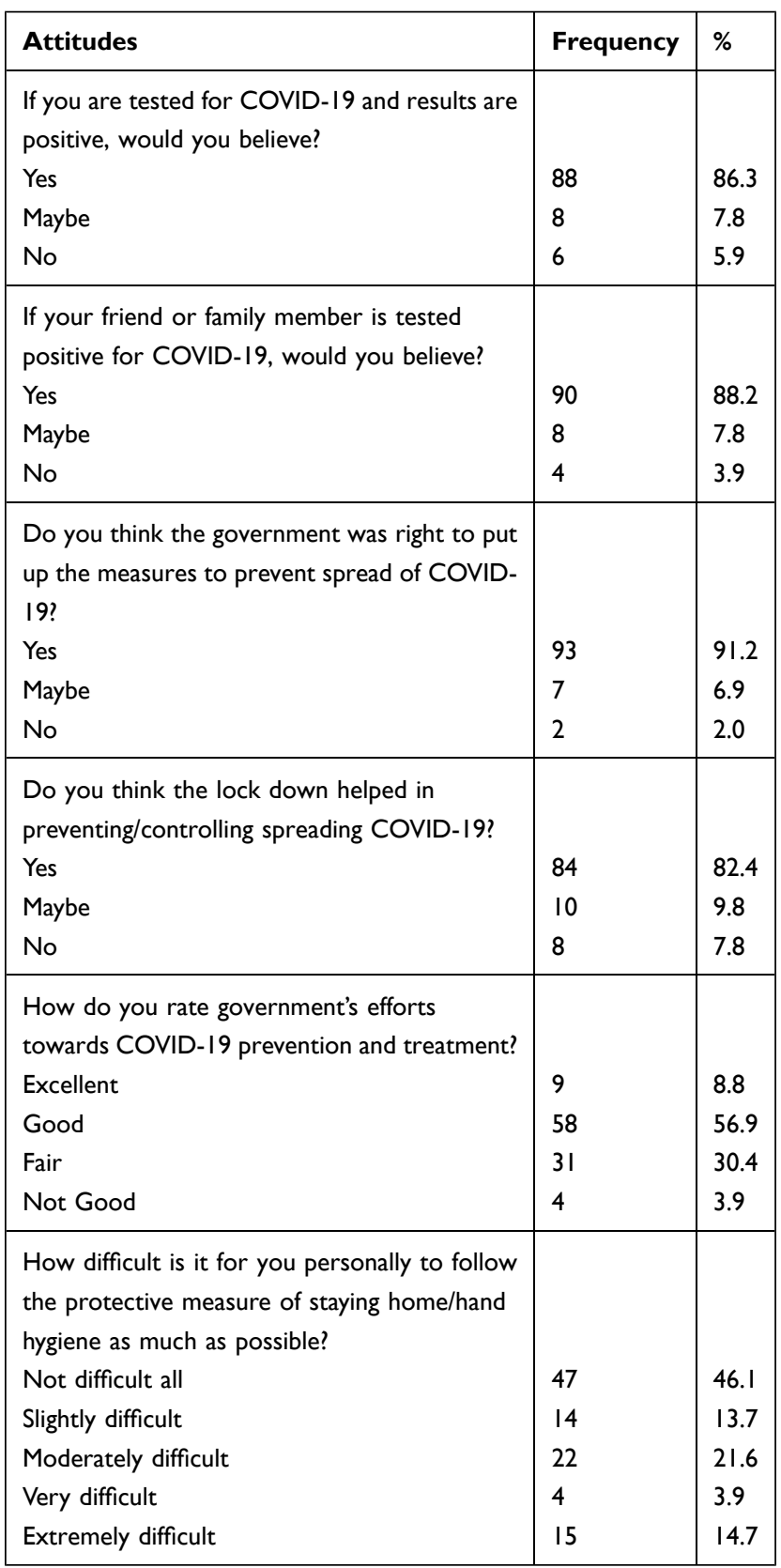

that done by Akalu and colleagues, which showed poor COVID-19 related practices among chronic disease patients in Addis Zemen Hospital, Northwest Ethiopia. ${ }^{13}$

Awareness about COVID-19 was significantly associated with COVID-19 related practices. This could be due to the fact that COVID-19 related practices are practiced after being aware of the disease and the activities themselves. It is also worth noting that, from this study, majority of the participants reported that it was not difficult to follow the stipulated COVID-19 preventive 
measures (hand washing, staying home or wearing face masks) which could as well explain the adequate practicing of the measures by the participants.

Our study has some important limitations that should be considered while interpreting the findings of the study. The study sample size was relatively small, thus limiting its generalization. Our study reports perceived practices rather than observed responses. Strict enforcement of COVID-19 guidelines at the time of the study therefore might have influenced some participants to give socially acceptable responses. The questionnaire used to assess KAPs was not standardized though internal reliability was checked using Cronbach's alpha and were within acceptable levels. Data on the medical condition of the patients were also not assessed during our study since it can have an impact on the KAPs towards COVID-19.

\section{Conclusion}

In conclusion, the study found that more than half of the participants had adequate knowledge and good practices on COVID-19 and its preventive measures, which is encouraging given that patients are a high risk group for severe COVID-19 illness. However, with the lifting and relaxation of the extreme preventive measures like lockdowns, continuous public education is recommended. Provision of handwashing facilities and personal protective equipment like facemasks to all patients are recommended.

\section{Abbreviations}

COVID-19, coronavirus disease 2019; MOH, Ministry of Health; WHO, World Health Organization; MNRH, Mulago National Referral Hospital.

\section{Data Sharing Statement}

Data obtained for the study will not be made available to others.

\section{Acknowledgments}

We acknowledge Makerere College of Health Sciences Students Association for the help accorded for this study to be a success.

We acknowledge Prof. Harriet Kizza Mayanja for reviewing the study protocol and guiding us towards the happening of this study.

We thank Mulago National Referral Hospital for allowing us do the study from its wards and approving our protocol. We would also like to thank all the participants that spent their time in order to get involved in this study and further appreciate Sister Erach Ruth and Sister Achuu Venny, who are nursing officers for Mulago Hospital for helping us with collection of data.

\section{Author Contributions}

All authors made a significant contribution to the work reported, whether that is in the conception, study design, execution, acquisition of data, analysis and interpretation, or in all these areas; took part in drafting, revising or critically reviewing the article; gave final approval of the version to be published; have agreed on the journal to which the article has been submitted; and agree to be accountable for all aspects of the work.

\section{Funding}

This study received no funding from any individual or organization. It was solely funded by the authors.

\section{Disclosure}

The authors report no potential conflicts of interest for this work and declare that the research was conducted in the absence of any commercial or financial relationships that could be construed as a potential conflict of interest.

\section{References}

1. Wu F, Zhao S, Yu B, et al. A new coronavirus associated with human respiratory disease in China. Nature. 2020;579:265-269. doi:10. 1038/s41586-020-2008-3

2. Zhou P, Yang X-L, Wang X-G, et al. A pneumonia outbreak associated with a new coronavirus of probable bat origin. Nature. 2020;579:270-273. doi:10.1038/s41586-020-2012-7

3. Woldometer. COVID-19 Coronavirus Pandemic; 2020 [cited October 24, 2020]. Available from: https://www.worldometers.info/ coronavirus/. Accessed December 17, 2020.

4. Riou J, Althaus CL. Pattern of early human-to-human transmission of Wuhan 2019-nCoV. bioRxiv. 2020;917351. doi:10.1101/2020.01.23. 917351.

5. Shi H, Han X, Jiang N, et al. Radiological findings from 81 patients with COVID-19 pneumonia in Wuhan, China: a descriptive study. Lancet Infect Dis. 2020;20:425-434. doi:10.1016/S1473-3099(20) 30086-4

6. Sahin AR, Erdogan A, Agaoglu PM, et al. 2019 novel coronavirus (COVID-19) outbreak: a review of the current literature. Eurasian J Med Oncol. 2020. doi:10.14744/ejmo.2020.12220

7. Ssebuufu R, Sikakulya F, Binezero SM, et al. Awareness, knowledge, attitude and practice towards measures for prevention of the spread of COVID-19 in the Ugandans: a nationwide online cross-sectional Survey. medRxiv. 2020.

8. Olum R, Bongomin F. Uganda's first 100 COVID-19 cases: trends and lessons. Int $J$ Infect Dis. 2020;96:517-518. doi:10.1016/j. ijid.2020.05.073

9. Besigye IK, Mulowooza M, Namatovu J. Coronavirus disease-2019 epidemic response in Uganda: the need to strengthen and engage primary healthcare. Afr J Prim Health Care Fam Med. $2020 ; 12$. 
10. The Independent. Kikuubo crowds enhancing COVID-19 transmissions. The Independent Newspaper [Internet]. [cited November 24, 2020]. Available from: http:/www.independent.co.ug/kikuubo-crowdsenhancing-covid-19-transmissions/. Accessed December 17, 2020.

11. Zhang J, Wang X, Jia X, et al. Risk factors for disease severity, unimprovement, and mortality in COVID-19 patients in Wuhan, China. Clin Microbiol Infect. 2020;26:767-772. doi:10.1016/j. cmi.2020.04.012

12. Geldsetzer P. Knowledge and perceptions of COVID-19 among the general public in the United States and the United Kingdom: a cross-sectional online survey. Ann Intern Med. 2020;173:157-160. doi:10.7326/M20-0912

13. Akalu Y, Ayelign B, Molla MD. Knowledge, attitude and practice towards COVID-19 among chronic disease patients at Addis Zemen Hospital, Northwest Ethiopia. Infect Drug Resist. 2020;13:1949-1960. doi:10.2147/IDR.S258736

14. Olum R, Kajjimu J, Kanyike AM, et al. Perspective of medical students on the COVID-19 pandemic: survey of Nine Medical Schools in Uganda. JMIR Public Health Surveill. 2020;6(2):e19847. doi: $10.2196 / 19847$

15. Olum R, Chekwech G, Wekha G, Nassozi DR, Bongomin F. Coronavirus disease-2019: knowledge, attitude, and practices of health care workers at Makerere University Teaching Hospitals, Uganda. Front Public Health. 2020. doi:10.3389/fpubh.2020.00181

16. Usman IM, Ssempijja F, Ssebuufu R, et al. Community drivers affecting adherence to WHO guidelines against covid-19 amongst rural Ugandan market vendors. Front Public Health. 2020;8:340. doi:10.3389/fpubh.2020.00340

17. Zhong B-L, Luo W, Li H-M, et al. Knowledge, attitudes, and practices towards COVID-19 among Chinese residents during the rapid rise period of the COVID-19 outbreak: a quick online cross-sectional survey. Int J Biol Sci. 2020;16:1745-1752. doi:10.7150/ijbs.45221

18. Muruganandam P, Neelamegam S, Menon V, Alexander J, Chaturvedi SK. COVID-19 and severe mental illness: impact on patients and its relation with their awareness about COVID-19. Psychiatry Res. 2020;291:113265. doi:10.1016/j.psychres.2020.113265
19. Li Z-H, Zhang X-R, Zhong W-F, et al. Knowledge, attitudes, and practices related to Coronavirus disease 2019 during the outbreak among workers in China: a large cross-sectional study. Gromowski G, editor. PLoS Negl Trop Dis. 2020;14:e0008584. doi:10.1371/journal.pntd.0008584

20. Huynh G, Nguyen TNH, Vo KN, Pham LA. Knowledge and attitude toward COVID-19 among healthcare workers at District 2 Hospital, Ho Chi Minh City. Asian Pac J Trop Med. 2020;13:260.

21. Reuben RC, Danladi MMA, Saleh DA, Ejembi PE. Knowledge, attitudes and practices towards COVID-19: an epidemiological survey in North-Central Nigeria. J Community Health. 2020. doi:10.1007/s10900-020-00881-1

22. Fisher WA, Fisher JD, Rye BJ. Understanding and promoting AIDS-preventive behavior: insights from the theory of reasoned action. Health Psychol. 1995;14:255-264. doi:10.1037/02786133.14.3.255

23. Azlan AA, Hamzah MR, Sern TJ, Ayub SH, Mohamad E. Public knowledge, attitudes and practices towards COVID-19: A cross-sectional study in Malaysia. Tu W-J, editor. PLoS One. 2020;15:e0233668. doi:10.1371/journal.pone.0233668

24. Atalan A. Is the lockdown important to prevent the COVID-19 pandemic? Effects on psychology, environment and economy-perspective. Ann Med Surg. 2020;56:38-42. doi:10.1016/j. amsu.2020.06.010

25. Echoru I, Usman IM, Ssempijja F, et al. Religion influences community adherence to COVID-19 guidelines in Uganda; 2020.

26. Saqlain M, Munir MM, Rehman SU, et al. Knowledge, attitude, practice and perceived barriers among healthcare workers regarding COVID-19: a cross-sectional survey from Pakistan. J Hosp Infect. 2020;105:419-423. doi:10.1016/j.jhin.2020.05.007
Risk Management and Healthcare Policy

\section{Publish your work in this journal}

Risk Management and Healthcare Policy is an international, peerreviewed, open access journal focusing on all aspects of public health, policy, and preventative measures to promote good health and improve morbidity and mortality in the population. The journal welcomes submitted papers covering original research, basic science, clinical \& epidemiological studies, reviews and evaluations,

\section{Dovepress}

guidelines, expert opinion and commentary, case reports and extended reports. The manuscript management system is completely online and includes a very quick and fair peer-review system, which is all easy to use. Visit http://www.dovepress.com/testimonials.php to read real quotes from published authors. 